\title{
Erratum to: Ceratonia siliqua pod extract ameliorates Schistosoma mansoni-induced liver fibrosis and oxidative stress
}

\author{
Ebtesam M. Al-Olayan 1,2, Manal F. El-Khadragy 1,2,3, Reem A. Alajmi', Mohamed S. Othman ${ }^{4,5}$, Amira A. Bauomy ${ }^{3,6}$, \\ Shaimaa R. Ibrahim ${ }^{7}$ and Ahmed E. Abdel Moneim ${ }^{3^{*}}$
}

\section{Erratum}

Following publication of the original article [1] it was brought to our attention that the affiliations for this article had been incorrectly presented. Please note that the correct affiliations should be as follows:

Ebtesam M. Al-Olayan ${ }^{1,2}$, Manal F. El-Khadragy ${ }^{1,2,3}$, Reem A. Alajmi ${ }^{1}$, Mohamed S. Othman ${ }^{4,5}$, Amira A. Bauomy $^{3,6}$, Shaimaa R. Ibrahim ${ }^{7}$ and Ahmed E. Abdel Moneim $^{3 "}$

${ }^{1}$ Chair vaccines research of infectious diseases, Faculty of Science, King Saud University, Riyadh, and KSA

${ }^{2}$ Department of Zoology, Faculty of Science, King Saud University, Riyadh, KSA

${ }^{3}$ Department of Zoology and Entomology, Faculty of Science, University of Helwan, Cairo, Egypt

${ }^{4}$ Faculty of Preparatory year, University of Hail, Hail, KSA

${ }^{5}$ Faculty of Biotechnology, October University for Modern Science and Arts (MSA), Giza, Egypt

${ }^{6}$ Laboratory Sciences Dept., College of Science and Arts, Qassim University, Al-Rass, KSA

${ }^{7}$ Molecular Drug Evaluation Department, National Organization for Drug Control \& Research (NODCAR), Giza, Egypt

Please also note that the Acknowledgements section should be updated to the following: "The authors extend their appreciation to the Deanship of Scientific Research at King Saud University for funding the work through the research group project No. RGPVPP-074".

\section{Author details}

'Chair vaccines research of infectious diseases, Faculty of Science, King Saud University, Riyadh, Kingdom of Saudi Arabia. ${ }^{2}$ Department of Zoology, Faculty of Science, King Saud University, Riyadh, Kingdom of Saudi Arabia.

${ }^{3}$ Department of Zoology and Entomology, Faculty of Science, University of
Helwan, Cairo, Egypt. ${ }^{4}$ Faculty of Preparatory year, University of Hail, Hail, Kingdom of Saudi Arabia. ${ }^{5}$ Faculty of Biotechnology, October University for Modern Science and Arts (MSA), Giza, Egypt. 'Laboratory Sciences Dept., College of Science and Arts, Qassim University, Al-Rass, Kingdom of Saudi Arabia. ${ }^{7}$ Molecular Drug Evaluation Department, National Organization for Drug Control \& Research (NODCAR), Giza, Egypt.

Received: 6 December 2016 Accepted: 6 December 2016 Published online: 17 January 2017

\section{Reference}

1. Al-Olayan EM, et al. Ceratonia siliqua pod extract ameliorates Schistosoma mansoni-induced liver fibrosis and oxidative stress. BMC Complementary and Alternative Medicine. 2016;16:434.

* Correspondence: aest1977@hotmail.com

${ }^{3}$ Department of Zoology and Entomology, Faculty of Science, University of Helwan, Cairo, Egypt 